\title{
INTEGRATED FIRE-STRUCTURE SIMULATION OF A LOCALZIED FIRE TEST ON A CEILING STEEL BEAM
}

\author{
Guo-Qiang $\mathrm{Li}^{1,2}$ and Chao Zhang ${ }^{2, *}$ \\ ${ }^{1}$ State Key Laboratory for Disaster Reduction in Civil Engineering, Tongji University, China \\ ${ }^{2}$ College of Civil Engineering, Tongji University, China \\ *(Corresponding author: E-mail:08_chao_zhang@tongji.edu.cn)
}

Received: 5 May 2016; Revised: 24 June 2016; Accepted: 1 July 2016

\begin{abstract}
Performance based method is increasingly used for structural fire safety design of modern buildings with large enclosure. The design fire scenarios in large enclosure are localized fires. Integrated fire-structure simulation method is required to accurately predict the response of structures in realistic fires (e.g. localized fires). In recent years, there is an increase in use of FDS (Fire Dynamics Simulator) - FEM (finite element method) approach for performance-based structural fire design. This paper discusses the FDS-FEM approach for predicting the thermal response of structures subjected to localized fires. A fire-structure interface, named adiabatic surface temperature $(A S T)$, was applied to transfer data from FDS to ANSYS. By comparing the predicted and measured heat fluxes and steel temperatures of a steel ceiling beam exposed to a localized fire condition, the FDS-FEM method was tested. The FDS predicted heat fluxes matched well with the test data. The difference between the predicted and measured maximum heat fluxes was within $6 \%$ for the investigated two cases. The FDS-FEM method gave good prediction of the steel temperatures. The over-prediction of maximum steel temperature was within $11 \%$ for the investigated case. The methods described in this study provide a feasible way to study the complex behavior of structures in realistic fires.
\end{abstract}

Keywords: Integrated fire-structure simulation, Fire Dynamics Simulation (FDS), Finite element method (FEM), Localized fire, Steel ceiling beam, Performance based design, Temperature

DOI: 10.18057/IJASC.2017.13.2.3

\section{INTRODUCTION}

At high temperature nearly all structural materials lose some of their strength and stiffness. Structural steel retains only about half of its room temperature yield strength and elastic modulus at about $550{ }^{\circ} \mathrm{C}$ [1]. Temperature induced thermal strain, if restrained, generates additional stress in structures which might accelerate structure failure in fire. Because steel has high conductivity and low heat capacity, when exposed to fire the bare steel structures elevate to a high temperature in a short time which might result in structure collapse before complete evacuation of the building. Bare steel structures' frangible to fire has been investigated in many disastrous fire accidents, typically the WTC fire [2] and the Windsor Tower fire [3]. Therefore, comparing with other structures such as concrete structures and masonry structures, the fire safety of steel structures is of primary importance.

Traditionally, the fire safety of steel structures is insured by requiring the structural steel components have sufficient fire resistance. The fire resistance of a building component is determined by a standard fire resistance test conducted on an isolated member subjected to a specified time temperature curve. The standard fire resistance test, which was developed more than a century ago, has been criticized for its shortcomings [4]:

- The standard temperature-time curve is not representative of a real fire in a real building. A real fire includes both heating and cooling phases while the standard fire curve does not decrease with time. Also, the standard fire represents a uniform heating condition while the heating condition in a real fire is non-uniform, e.g. gas temperature distribution in localized fires in large enclosure is highly non-uniform spatially [5]. 
- The behaviour of the isolated members cannot represent the behaviour of the components in an entire structure. In a real building, a component is restrained by the surrounding structures. The restraints induce thermal stress in the heated component and also might activate alternative load-bearing modes (e.g., membrane action of composite floor slab [6, 7] and catenary action of restrained beams [8,9]). Furthermore, there exist alternative load paths in restrained components. In entire structures, when some structural components begin to fail, the adjacent components will restrain to resist the further failure of the weakened components.

As a result, the design approach based on the standard fire cannot assess the actual level of safety of a structure exposed to fire and usually yields a fire protection design that is too conservative, which has been proved by both accident fires (e.g. the Broadgate Phase 8 fire [10]) and real fire tests (e.g. the Cardington full-scale fire test [11]). It should be noted, however, that a fire protection design based on a standard fire test or prescriptive code is not guaranteed to be conservative, as being found by recent numerical studies [12-15].

Over the past 30 years, there have been significant advances in structural fire research. New insights, data, and calculation methods have been reported, which form the basis for modern performance-based (PB) codes for structural fire safety [16]. The PB approach involves the assessment of the structural response in real fires and, therefore, requires advanced computational approaches for fire and structural modeling. Sophisticated computational fluid dynamics (CFD) models are typically used to simulate realistic fires [5], while finite element method (FEM) codes are mostly used for structural modeling [12-15, 17]. An integrated CFD-FEM simulation approach is needed for advanced structural fire analysis [18]. Fire Dynamics Simulator (FDS) is an open source CFD code, developed by NIST [19]. It has been widely used in fire engineering for modeling the gas phase environment (temperature, heat flux, velocity, species concentrations, etc.) in fires. Recently, there has been increased research in the application of FDS for structural fire analysis [20, 21]. Fire-structure interface tools for transferring data from FDS to particular FEM codes (such as ANSYS, ABAQUS, SAFIR) have been developed [21]. Although the FDS-FEM simulation approach has been used in practical projects [22, 23], validation of the integrated fire-structure simulation method is quite limited [24]. This paper presents a validation study of the integrated FDS-FEM simulation methodology against a localized fire test on a steel ceiling I beam reported by Hasemi et al. [25, 26]. This localized fire test was selected for model validation because of the applicability to real-world thermal conditions and because the test was well controlled (e.g. the heat release rate of the fire was controlled by computer), and detailedly measured.

\section{INTEGRATED FIRE-STRUCTURE SIMULATION METHODOLOGY}

\subsection{The CFD-FEM Approach}

Figure 1 illustrates the CFD-FEM simulation approach for structural fire analysis. The fire-structure interaction is fundamentally two-way, while one-way coupling may be advantageous under certain conditions [18]. In a one-way coupling, the Navier-Stokes equations, radiation transport equations, etc., for the fluid domain in a fire compartment are solved for the complete time duration of interest by a CFD code to get gas temperatures, velocities, chemical species, incident heat fluxes, film coefficients, etc. The heat equations for the solid domain (building elements) use the thermal boundaries from the CFD simulation to get the thermal response (temperature rise) within the building elements. Kinematics equations, constitutive equations, etc., for the solid domain are solved by a FEM code to get the deformations, stresses, strains, etc. Fire-structure and thermo-mechanical interfaces are used to transfer data between different models. In a two-way 
coupling, the same set of equations is solved except that at discrete time steps through the simulation the solid phase FEM code provides feedback to update the CFD model.

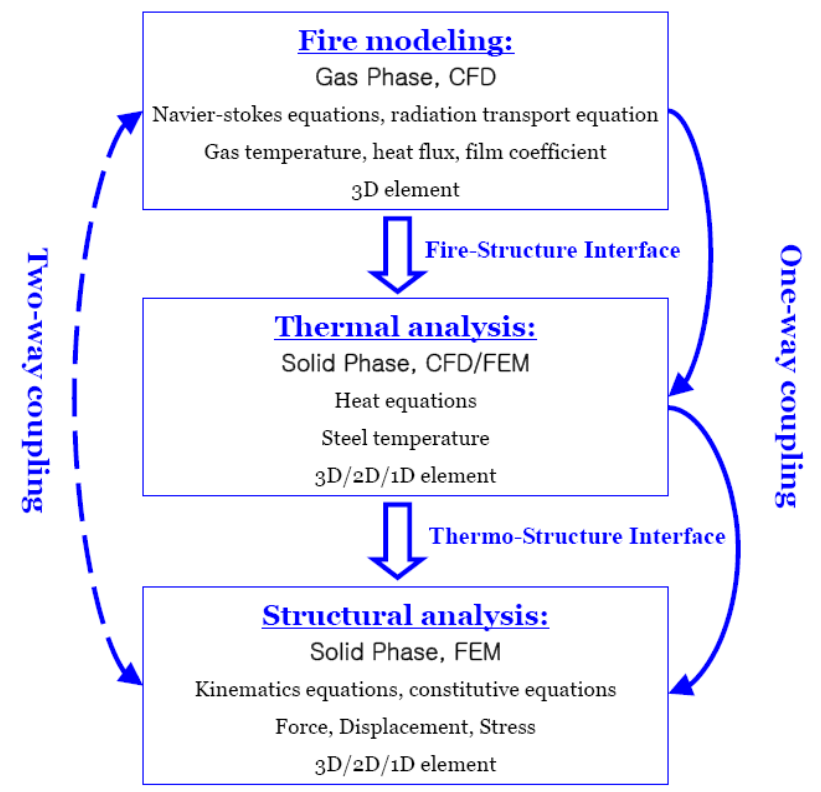

Figure 1. Coupled CFD-FEM Simulation Approach for Structural Fire Analysis [24]

\section{$2.2 \quad$ The FDS Code}

Fire Dynamics Simulator (FDS) is a large-eddy simulation (LES) based CFD code [19]. In this study, FDS version 5 is used. LES is a technique used to model the dissipative processes (viscosity, thermal conductivity, material diffusivity) that occur at length scales smaller than those that are explicitly resolved on the numerical grid. In FDS, the combustion is based on the mixing-limited, infinitely fast reaction of lumped species, which are reacting scalars that represent mixtures of species. Thermal radiation is computed by solving the radiation transport equation for gray gas using the Finite Volume Method (FVM) on the same grid as the flow solver. FVM is based on a discretization of the integral forms of the conservation equations. It divides the problem domain into a set of discrete control volumes (CVs) and node points are used within these CVs for interpolating appropriate field variables. The governing equations are approximated on one or more rectilinear grids. Obstructions with complex geometries are approximated with groups of prescribed rectangles in FDS. One-dimensional (1D) heat conduction is assumed for solid-phase calculations. Detailed descriptions of the mathematical models used in FDS can be found in [19].

\subsection{The Fire Structure Interface}

The concept of adiabatic surface temperature is used to transfer thermal boundary data from a FDS model to a FEM model. Consider an ideal adiabatic surface exposed to a heating condition; the net heat flux to the surface is by definition zero, thus

$$
\varepsilon_{A S}\left(\dot{q}_{i n}^{\prime \prime}-\sigma T_{A S}^{4}\right)+h_{c, A S}\left(T_{g}-T_{A S}\right)=0
$$

where $\varepsilon_{A S}$ is emissivity of the adiabatic surface; $T_{A S}$ is temperature of the adiabatic surface or adiabatic surface temperature; and $h_{c, A S}$ is film coefficient between the adiabatic surface and the surrounding gas. 
From Eq. 1, the incident radiative flux to a surface can be calculated from an adiabatic surface temperature,

$\dot{q}_{i n}^{\prime \prime}=\frac{h_{c, A S}\left(T_{A S}-T_{g}\right)}{\varepsilon_{A S}}+\sigma T_{A S}^{4}$

Consider a real surface exposed to the same heating condition, the net heat flux to the surface can be calculated by

$\dot{q}^{\prime \prime}=\varepsilon_{S} \sigma\left(T_{A S}^{4}-T_{s}^{4}\right)+\frac{\varepsilon_{s}}{\varepsilon_{A S}} h_{c, A S}\left(T_{A S}-T_{g}\right)+h_{c}\left(T_{g}-T_{S}\right)$

If the emissivity of the adiabatic surface is taken as the emissivity of the real surface $\left(\varepsilon_{A S}=\varepsilon_{s}\right)$, and the film coefficient between the adiabatic surface and the surrounding gas is equal to the film coefficient between the real surface and the surrounding gas $\left(h_{c, A S}=h_{c}\right)$, we get

$\dot{q}^{\prime \prime}=\varepsilon_{S} \sigma\left(T_{A S}^{4}-T_{S}^{4}\right)+h_{c}\left(T_{A S}-T_{S}\right)$

Eq. 4 shows that the net heat flux to a surface can be approximately calculated by using a single parameter $T_{A S}$. In practice, the adiabatic surface temperatures of interest can be approximately measured by a plate thermometer [27]. Consider the case at high temperature (above about $400{ }^{\circ} \mathrm{C}$ ), where convection is not the dominant mode of heat transfer in fire [28]; from Eq. 3 or 4 the adiabatic surface temperature measured by a plate thermometer can be used to predict the net heat flux to a surface with a different emissivity. FDS [18] includes an output quantity of adiabatic surface temperature calculated by Eq. 4 according to the idea proposed by Wickstrom [29]. It should be noted that the calculated adiabatic temperature of a surface is fundamentally influenced by the convection or film coefficient (see Eq. 3) so that the value for film coefficient should be carefully selected when using the concept for calculations where convection is important [30].

\section{VALIDATION STUDY}

\subsection{Description of the Experiment}

Figure 2 shows the experimental layout in Hasemi et al.'s experiments [26]. The rectangular flat ceiling consists of two layers of $12 \mathrm{~mm}$ thick mineral fiber Perlite board with dimensions $1.83 \times 3.60 \times 0.024 \mathrm{~m}$. The ceiling is reinforced by a steel frame and is horizontally placed over the beam held by two steel vertical posts at the ends. H-section bare steel beam with the following dimensions was used: $3.6 \mathrm{~m}$ long, $75 \mathrm{~mm}$ width, $150 \mathrm{~mm}$ height, $5 \mathrm{~mm}$ (thickness of web), $6 \mathrm{~mm}$ (thickness of flange). The height of the beam and the ceiling was adjusted by lifting these specimens up and down the posts. Heat flux measurements were made at nine horizontal distances from the stagnation point of the beam. Water-cooled Schmidt-Boelter heat flux gauges were installed flush with the beam surface through the holes made in the beam shown in Figure 2. The heat flux to the upper flange, web and also lower and upper surfaces of the lower flange was measured. Temperature measurements were made with thermocouples at 27 points, arranged symmetrically to the points of the heat flux gauges with regard to the center of the beam. Thermocouples were $0.2 \mathrm{~mm}$ K-type and were installed $0.5 \mathrm{~mm}$ from the beam surface, as shown in Figure 2. A $0.5 \mathrm{~m}$ diameter round and a $1.0 \mathrm{~m}$ square porous propane burner were used as the fire source. 


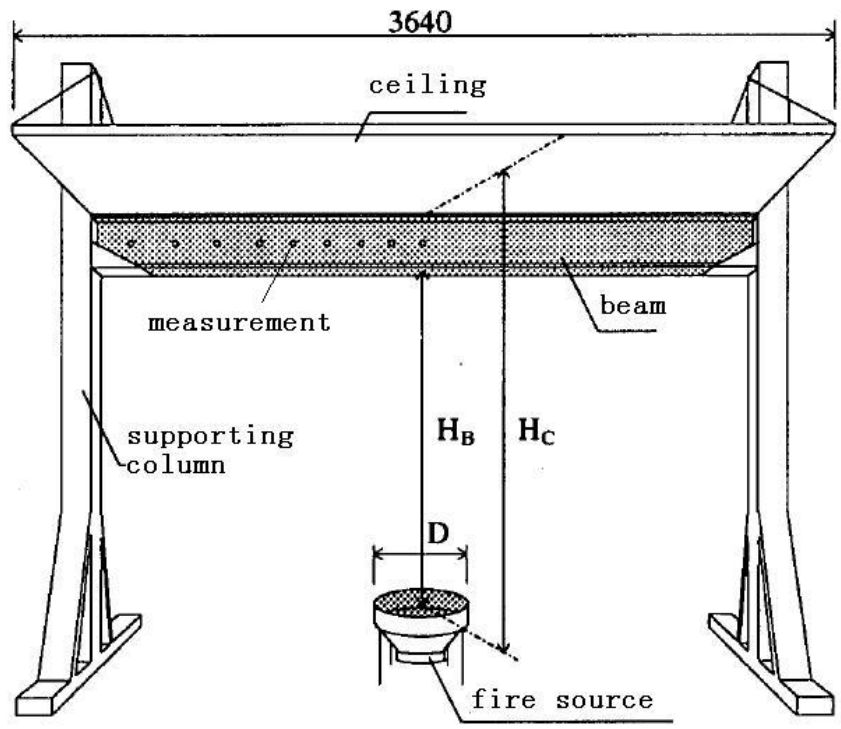

(a) Experimental setup

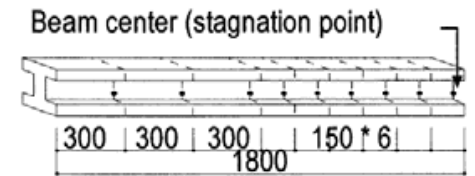

Locations of heat flux measurement, $\mathrm{mm}$

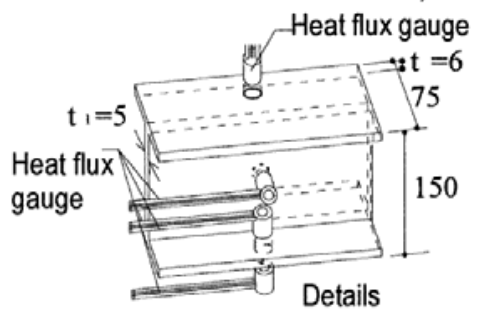

(b) Heat flux measurement

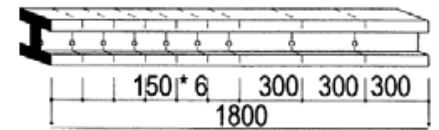

Locations of temperature measurement

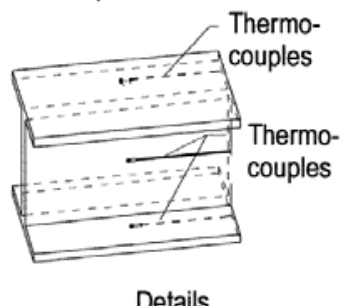

(c) Temperature measurement

Figure 2. Experimental Setup and Measurements in Hasemi etal.’s Test [26]

\subsection{FDS Numerical Model}

Figure 3 shows the FDS numerical model for the localized fire test cases using $1.0 \mathrm{~m}$ square burner in [26]. Two cases with steady heat release rates of $540 \mathrm{~kW}$ and $900 \mathrm{~kW}$ were considered. In both cases, the distance from the burner to the lower flange of the ceiling beam was $1.2 \mathrm{~m}$. The computational domain had dimensions of $4.0 \mathrm{~m}(\mathrm{X}) \times 2.0 \mathrm{~m}(\mathrm{Y}) \times 1.8 \mathrm{~m}(\mathrm{Z})$. Boundary conditions at four sides of the computational domain are opening. The flanges and web of the beam were modeled as steel sheets with thickness of $6 \mathrm{~mm}$. Both ceiling and floor were molded as $24 \mathrm{~mm}$ thick perlite boards. The densities of steel and perlite were $7850 \mathrm{~kg} / \mathrm{m}^{3}$ and $789 \mathrm{~kg} / \mathrm{m}^{3}$ [31]. The emissivity of all solid surfaces was taken as 0.9 [31]. Other properties of the materials were taken from [31]

$$
\begin{aligned}
& c_{s}=582.3-0.8896 T+2.289 \times 10^{-3} T^{2}-1.486 \times 10^{-6} T^{3}+2.97 \times 10^{-10} T^{4} \\
& c_{p}=1493-4.658 T+0.013743 T^{2}-1.4585 \times 10^{-4} T^{3}+5.128 \times 10^{-9} T^{4} \\
& k_{s}=70.45-0.02767 T-4.847 \times 10^{-5} T^{2}+4.722 \times 10^{-8} T^{3}-1.068 \times 10^{-11} T^{4} \\
& k_{p}=0.3314-8.834 \times 10^{-4} T+1.932 \times 10^{-6} T^{2}-1.96 \times 10^{-9} T^{3}+7.226 \times 10^{-13} T^{4}
\end{aligned}
$$


where $c_{s}, \rho_{s}$ are the specific heat of steel and perlite respectively; $k_{s}, k_{p}$ are the conductivity of the steel and perlite respectively.

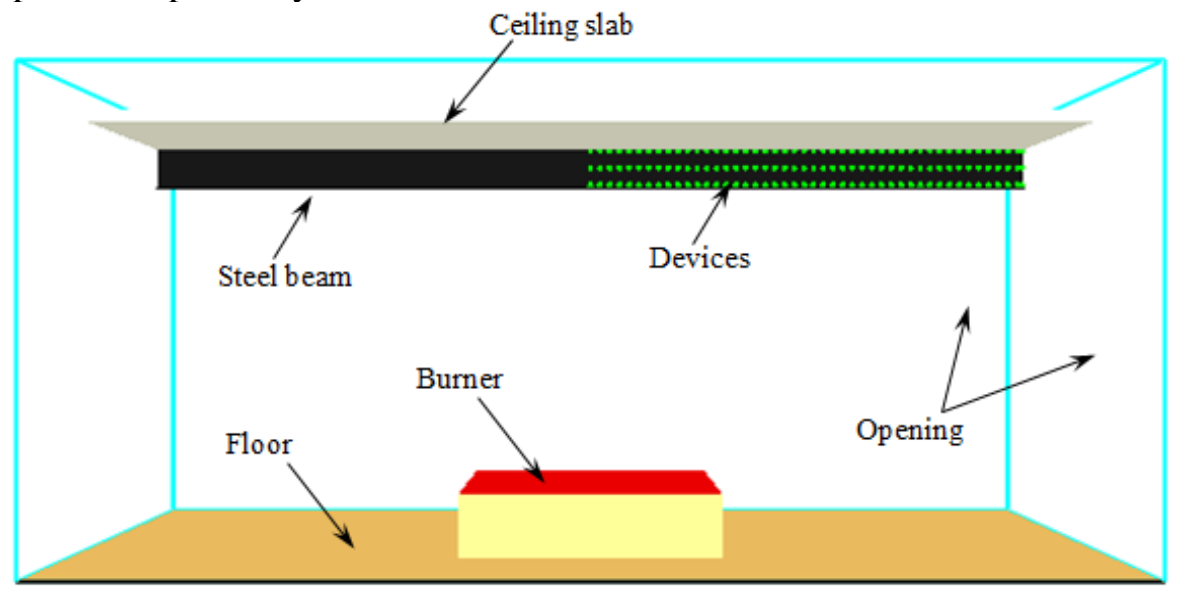

(a)

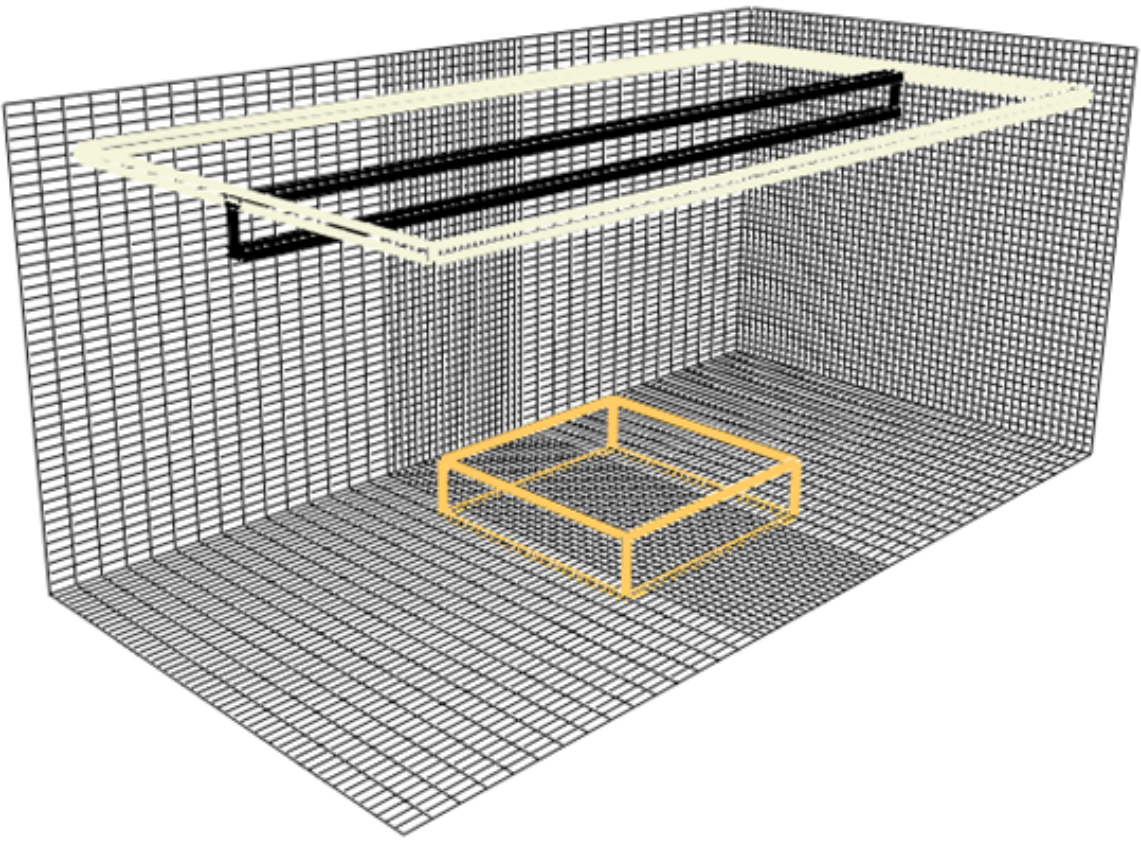

(b)

Figure 3. FDS Model for the Investigated Localized Fire Case

The grid sizes used is one of the most important numerical parameter in CFD dictating its numerical accuracy. The necessary spatial resolution for a proper LES simulation is customary defined in terms of the characteristic diameter of a plume, which is defined as [19],

$$
D^{*}=\left(\frac{\dot{Q}}{\rho_{\infty} c_{p} T_{\infty} \sqrt{g}}\right)^{2 / 5}
$$

The special resolution $R^{*}$ of a numerical grid is defined as,

$$
R^{*}=\frac{\delta x}{D^{*}}
$$


where $\delta x$ is the characteristic length of a cell for a given grid. The necessary resolution suggested in most studies is between 1/5 and 1/20 [19]. For the FDS model, the whole domain consisted of 50 $(\mathrm{X}) \times 50(\mathrm{Y}) \times 45(\mathrm{Z})=112,500$ control volumes. The grids in the $\mathrm{Y}$ and $\mathrm{Z}$ directions were uniform $(4 \mathrm{~cm})$, where that in the $X$ direction was stretched to yield the grid size in the flame region of $4 \mathrm{~cm}$. Therefore, the resolution at the flame region was about $1 / 23$ for $900 \mathrm{~kW}$ and about $1 / 19$ for 450 $\mathrm{kW}$.

\subsection{FEM Thermal Model}

Figure 4 shows the FEM model for the ceiling beam composite. By symmetry, a quarter of the composite was used. By the consideration that the temperatures of the lower flange and web of the steel I beam were not significantly affected by the thermal conduction from the ceiling slab, the width of the ceiling slab was taken as a half of the steel I beam in the FE model. The three dimensional (3D) layered shell element SHELL131 in ANSYS was used. SHELL131 has in-plane and through-thickness thermal conduction capacity. It has 4 nodes with up to 32 temperature degrees of freedom at each node. Thermal conduction through-thickness for the lower flange and the web of the steel I beam was ignored because of the high conductivity of steel. The composite section of the steel upper flange and perlite slab was divided into one steel layer and 5 perlite layers to consider thermal conduction between the upper flange and the slab (Figure 4b). As shown in Figure 4c, an additional external node was defined for each element (SHELL131) to apply the thermal boundary condition using the concept of adiabatic surface temperature $(A S T)$. The temperature of the external node was taken as the $A S T$ for the element (surface) transferred from FDS.

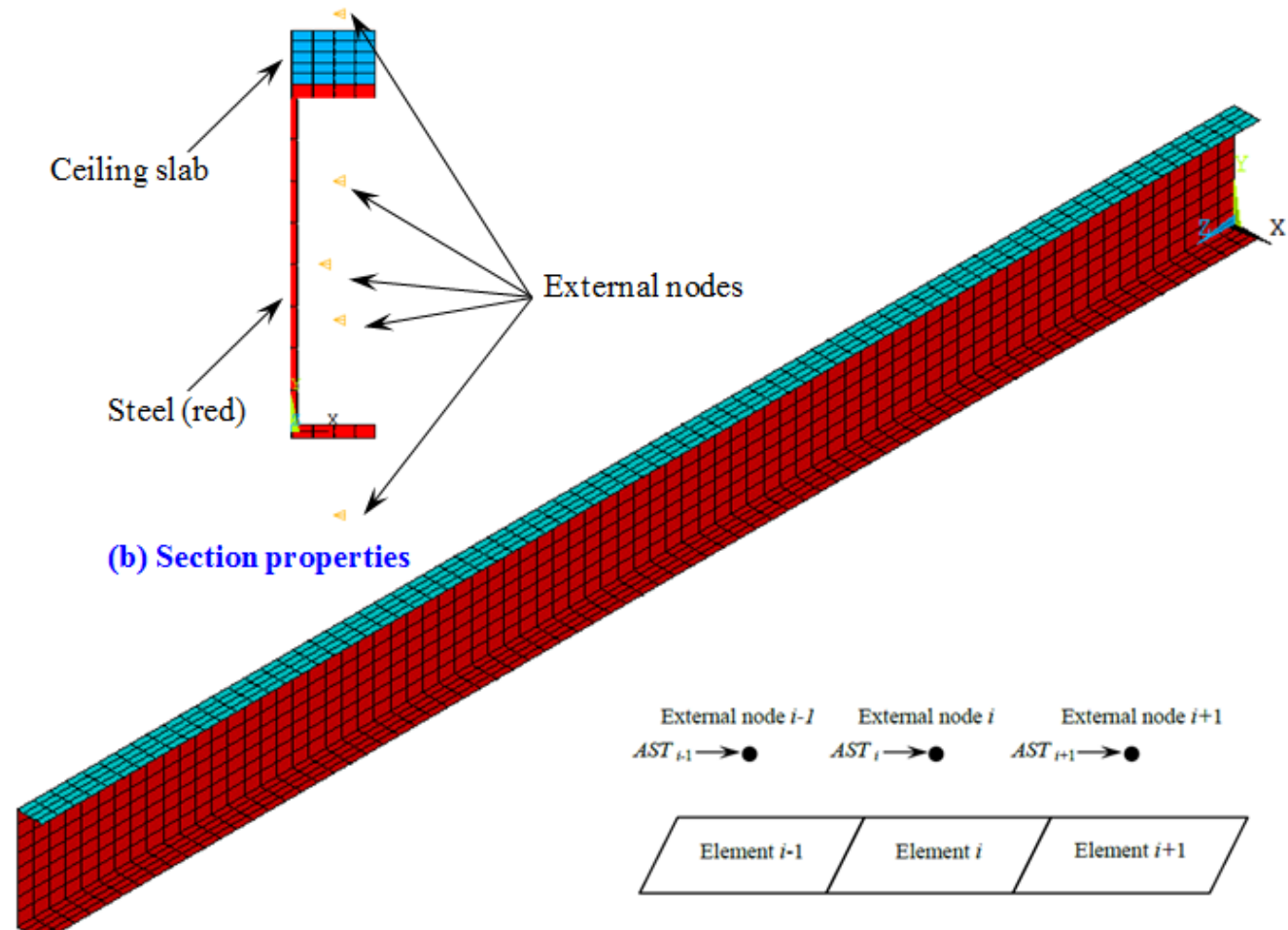

(a) Mesh of the composite beam

(c) Thermal boundary condition

Figure 4. FE Model for the Investigated Localized Fire Case 


\section{RESULTS AND DISCUSSION}

Figure 5 shows the time history of the heat fluxes and adiabatic surface temperatures (ASTs) predicted by FDS. The fluctuation of the curves is due to the turbulent combustion behavior. Figure 6 shows the time averaged $A S T$ s along the length of the beam. The unsmoothness of the curves is because the measured value of a point located in a control volume is taken as the value of the nearby grid point. The horizontal axis, $x$, is the distance to the beam center. ASTs decrease with increasing the distanced to the beam center. Generally, the bottom surface of the lower flange has the highest $A S T$ s. The other surfaces have similar $A S T$ s.

Figures 7 and 8 show the good match between the FDS predicted heat fluxes and the test data. The difference between the predicted and measured maximum heat fluxes was about $3 \mathrm{~kW} / \mathrm{m} 2$ (about $7 \%$ ) for the $540 \mathrm{~kW}$ case and about $5 \mathrm{~kW} / \mathrm{m} 2$ (about 6\%) for the $900 \mathrm{~kW}$ case. Figure 9 compares the FDS-FEM predicted steel temperatures with the test data. For the lower flange and the web of the steel I beam, the predicted steel temperatures agree very well with the test data. The over-prediction of maximum steel temperature for the lower flange is about $60{ }^{\circ} \mathrm{C}$ (about $11 \%$ ) and for the web is about $44{ }^{\circ} \mathrm{C}$ (about $8 \%$ ). The under-prediction of the upper flange steel temperature is caused by the ignoration of the horizontal heat conduction between the nearby slab to the steel section. Figure 10b shows the distribution of the ASTs on the exposed surfaces. Because of the flame impingement (Figure 10a) the $A S T$ s on the slab surface were higher than those on the upper flange surface, which indicted that heat fluxes were transferred from the slab to the steel in some area.

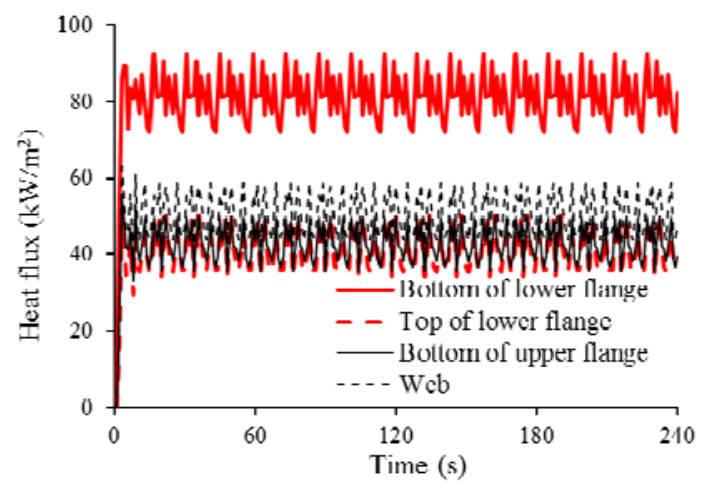

(a) Heat flux

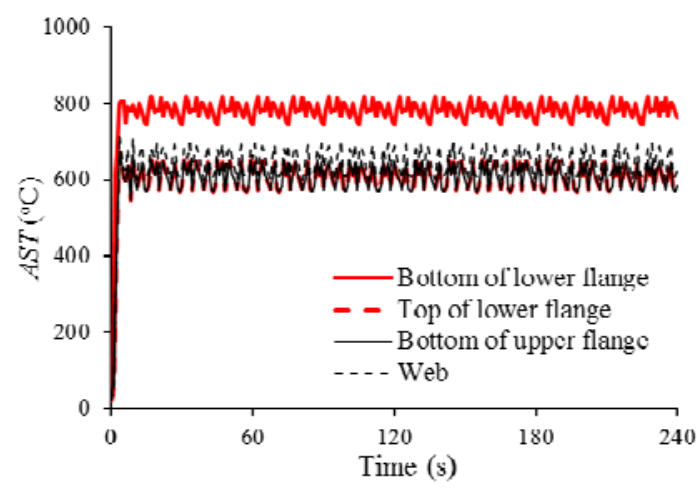

(b) $A S T$

Figure 5. Time History of FDS Predicted Heat Fluxes and $A S T \mathrm{~s}$ (900 kW case)

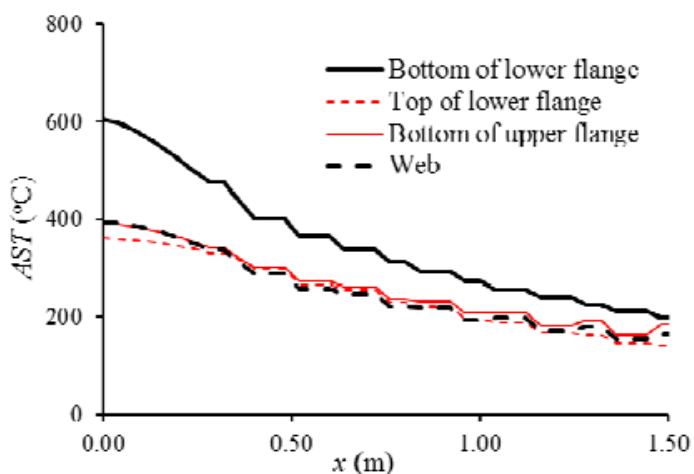

(a) $450 \mathrm{~kW}$

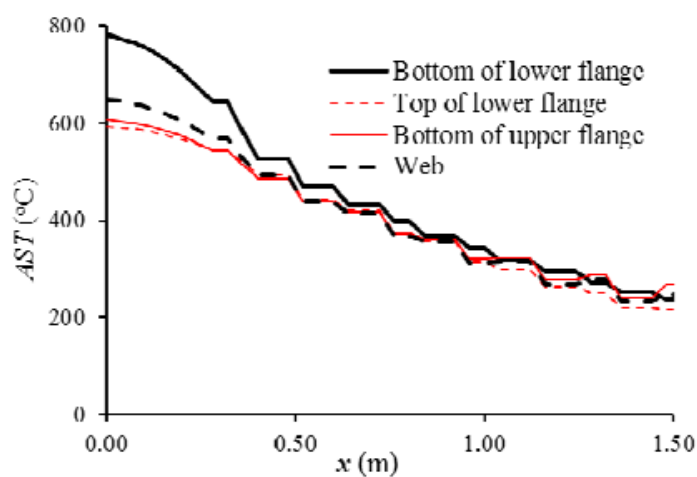

(b) $900 \mathrm{~kW}$

Figure 6. Time Averaged ASTs 


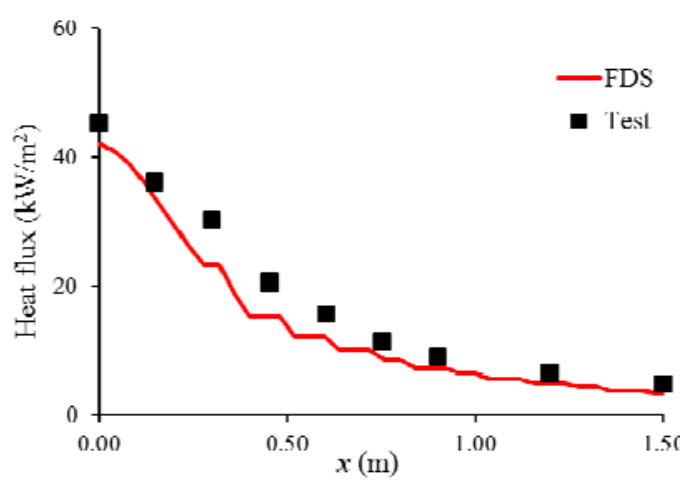

(a) Bottom of lower flange

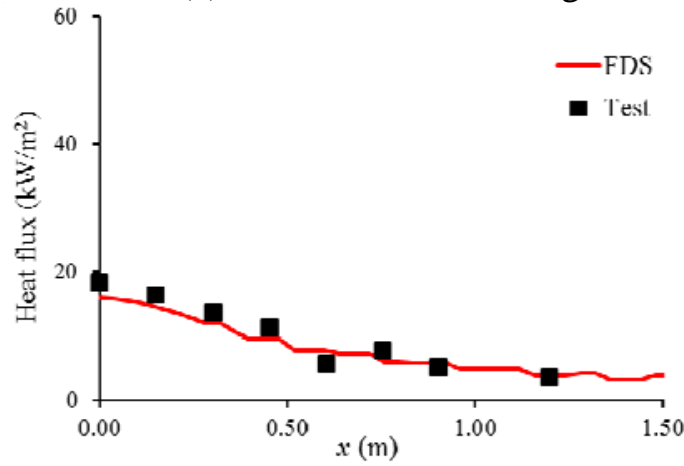

(c) Bottom of upper flange

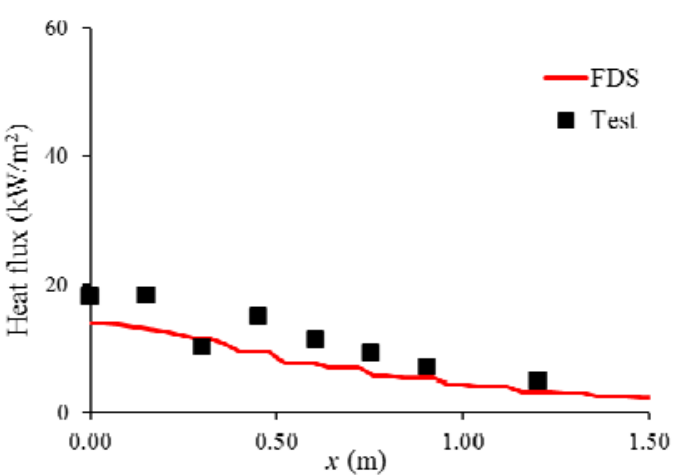

(b) Top of lower flange

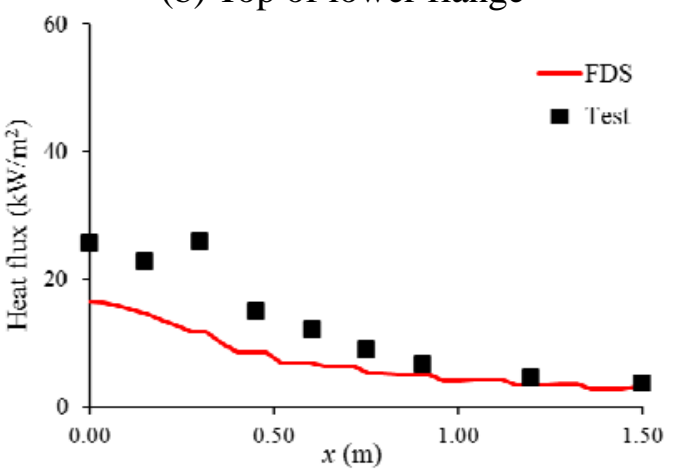

(d) web

Figure 7. FDS Predicted Heat Fluxes and the Test Data for the Investigated Case with HRR of $450 \mathrm{~kW}$

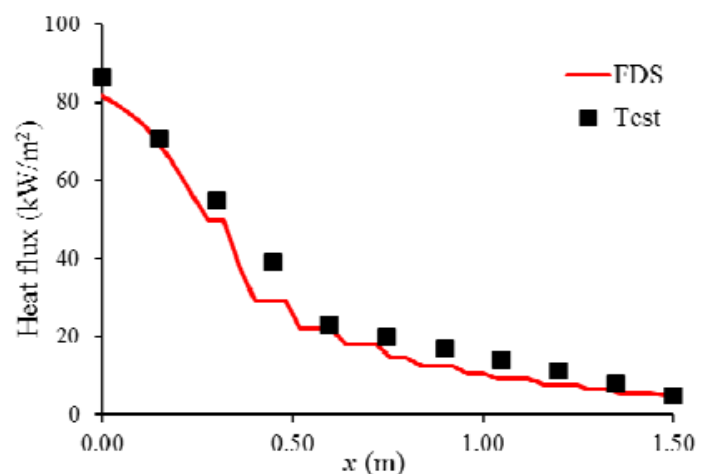

(a) Bottom of lower flange

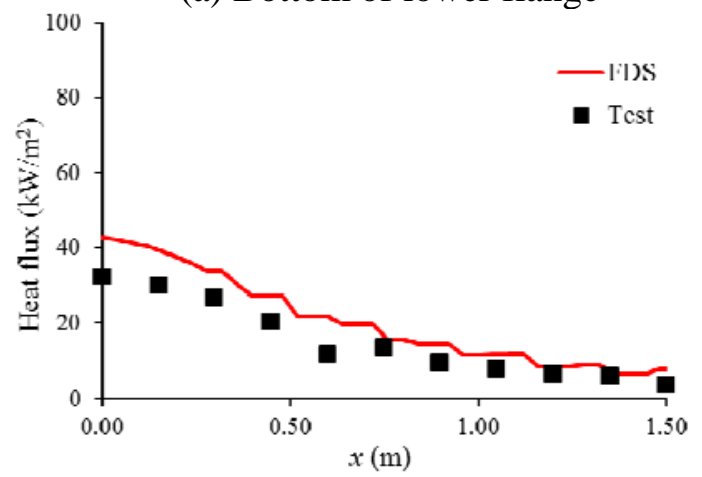

(c) Bottom of upper flange

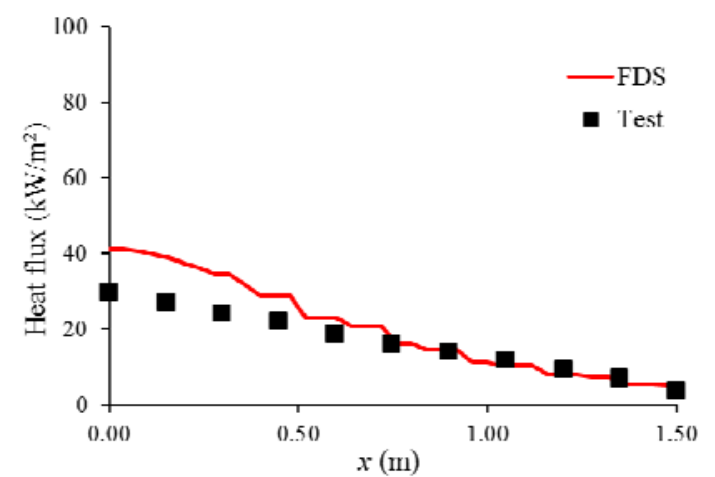

(b) Top of lower flange

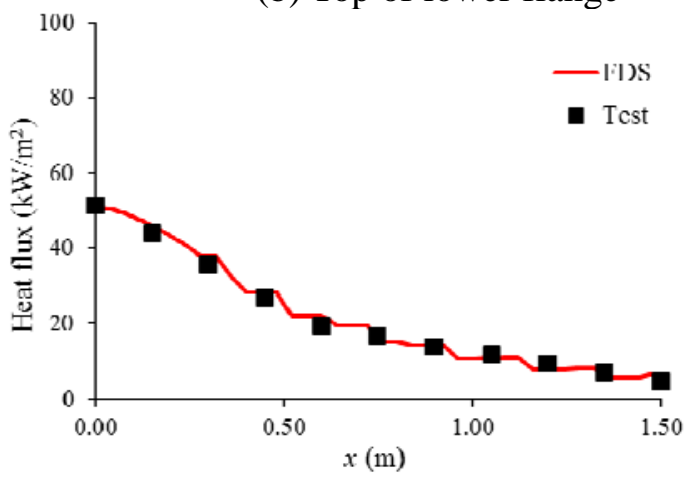

(d) web

Figure 8. FDS Predicted Heat Fluxes and Test Data for the Investigated Case with HRR of $900 \mathrm{~kW}$ 


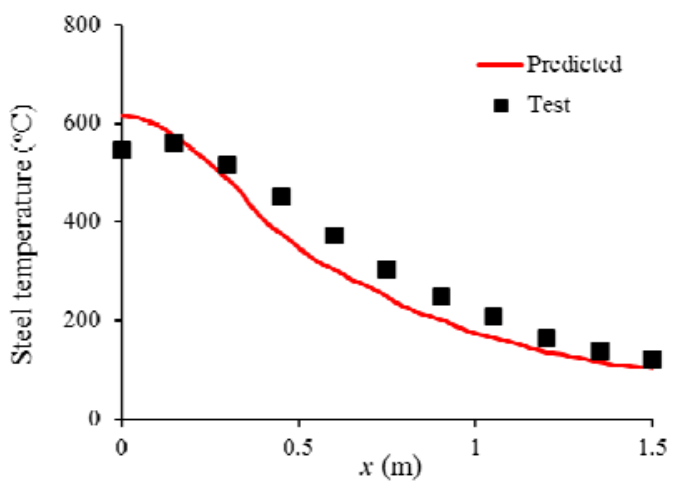

(a) Lower flange

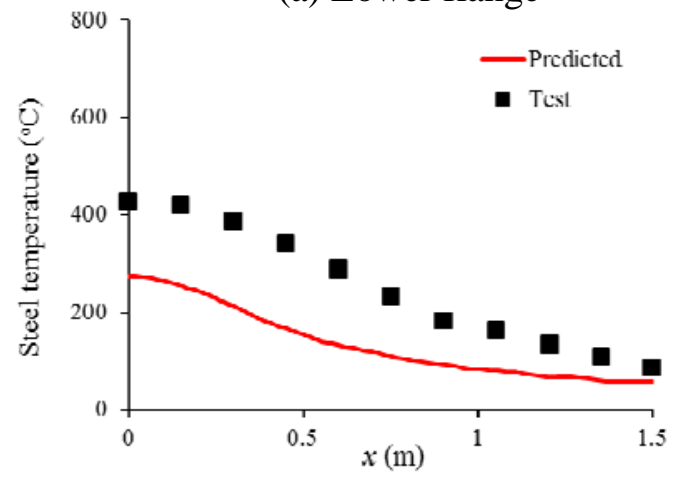

(c) Upper flange

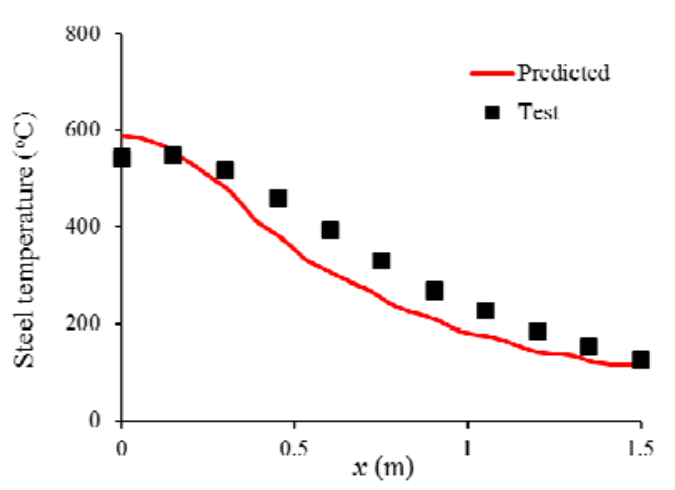

(b) Web

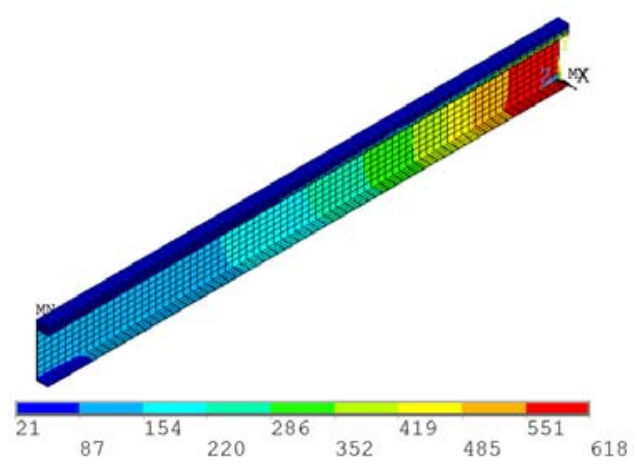

(d) Steel temperature distribution

Figure 9. FDS-FEM Predicted Steel Temperatures for the Investigated Case with HRR of $900 \mathrm{~kW}$

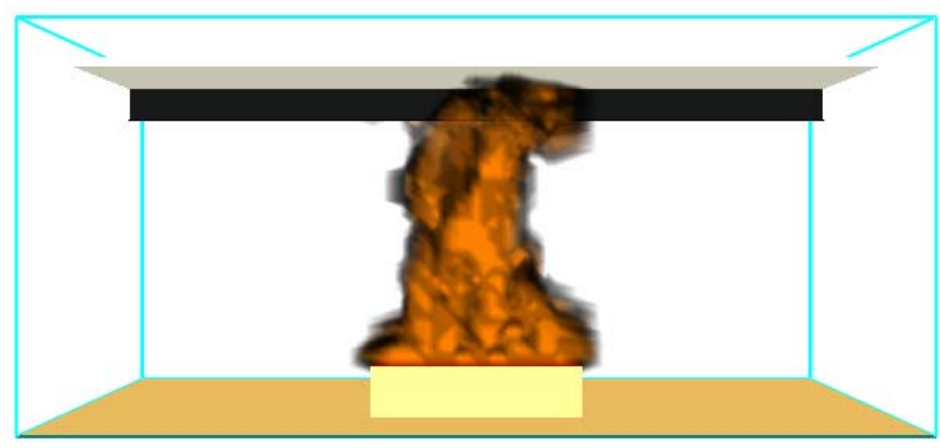

(a) Flame

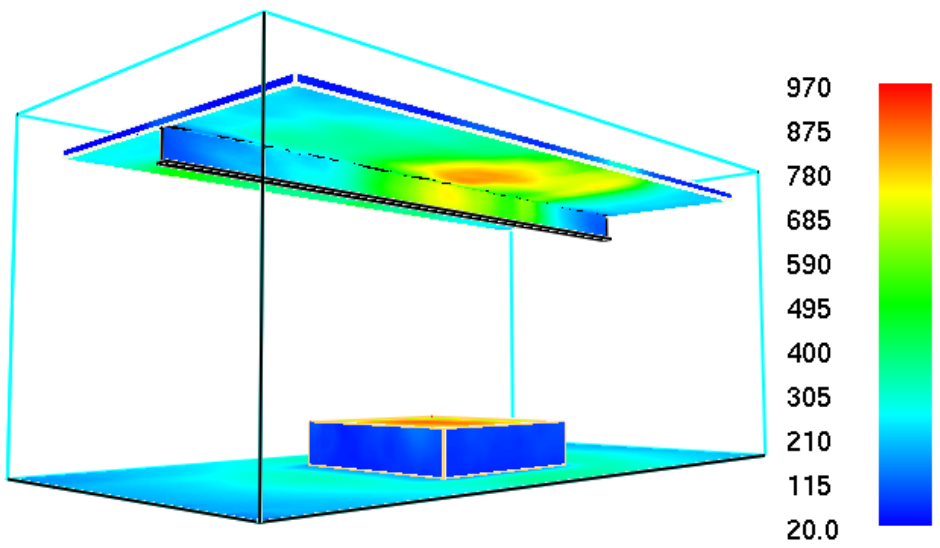

(b) Adiabatic surface temperature

Figure 10. FDS Predicted Adiabatic Surface Temperature 


\section{CONCLUSIONS}

This paper discusses the integrated fire-structure simulation methodology for performance based fire safety design. A fire-structure interface, named adiabatic surface temperature, was applied to transfer data from FDS to ANSYS. By comparing the predicted and measured heat fluxes and steel temperatures of a steel ceiling beam exposed to a localized fire condition, the FDS-FEM method was tested. The FDS predicted heat fluxes match well with the test data. The difference between the predicted and measured maximum heat fluxes was within $6 \%$ for the investigated two cases. The FDS-FEM method gave good prediction of the steel temperatures. The over-prediction of maximum steel temperature was within $11 \%$ for the investigated case. The methods described in this study provide a feasible way to study the complex behavior of structures in realistic fires.

\section{REFERENCES}

[1] BSI. Eurocode 3: Design of Steel Structures, Part 1.2: General Rules - Structural Fire Design. British Standard, 2005.

[2] McAllister, T,P,, Gann, R.G., Averill, J.D., Gross, J.L., Grosshandler, W.L., Lawson, J.R., McGrattan, K.B., Nelson, H.E., Pitts, W.M., Prasad, K.R. and Sadek, F.H., "Federal Building and Fire Safety Investigation of the World Trade Center Disaster: Structural Fire Response and Probable Collapse Sequence of World Trade Center Building 7. NIST NCSTAR 1-9”, National Institute of Standards and Technology, Gaithersburg, MD, USA, 2008.

[3] National Institute for Land and Infrastructure Management (NILIM). Report on the Windsor Building Fire in Madrid, Spain, Japan, 2005.

[4] Garlock, M., Kruppa, J., Li, G.Q. and Zhao, B., "Fire Behavior of Steel Structures (White Paper)”, Fire Resistance Structures Workshop, NIST, May 2014.

[5] Zhang, C. and Li, G.Q., "Fire Dynamic Simulation on Thermal Actions in Localized Fires in Large Enclosure”, Advanced Steel Construction, 2012, Vol. 8, pp. 124-36.

[6] Bailey, C.G., "Membrane Action of Unrestrained Lightly Reinforced Concrete Slabs at Large Displacements”, Engineering Structures, 2001, Vol. 23, pp. 470-83.

[7] Li, G.Q., Guo, S.X. and Zhou, H.S., "Modeling of Membrane Action in Floor Slabs Subjected to Fire”, Engineering Structures, 2007, Vol. 29, pp. 880-87.

[8] Liu, T.C.H., Fahad, M.K. and Davies, J.M., "Experimental Investigation of Behaviour of Axially Restrained Steel Beams in Fire”, Journal of Constructional Steel Research, 2002, Vol. 58, pp. 1211-30.

[9] Li, G.Q. and Guo, S.X., "Experiment on Restrained Steel Beams Subjected to Heating and Cooling”, Journal of Constructional Steel Research, 2008, Vol. 64, pp. 268-74.

[10] SCI P113. Structural Fire Engineering: Investigation of Broadgate Phase 8 Fire, The Steel Construction Institute, 1991.

[11] Kirby, B.R., “The Behaviour of a Multi-story Steel Framed Building Subjected to Fire Attack, Experimental Data”, British Steel, 2000.

[12] Zhang, C., Li, G.Q. and Usmani, A., "Simulating the Behavior of Restrained Steel Beams to Flame Impinged Localized Fires”, Journal of Constructional Steel Research, 2013, Vol. 83, pp. 156-65.

[13] Zhang, C., Gross, J,L, and McAllister, T., "Lateral Torsional Buckling of Steel W-beams to Localized Fires”, Journal of Constructional Steel Research, 2013, Vol. 88, pp. 330-8.

[14] Zhang, C., Gross, J.L., McAllister, T.P. and Li, G.Q., "Behavior of Unrestrained and Restrained Bare Steel Columns Subjected to Localized Fire”, Journal of Structural Engineering-ASCE, 2015, Vol.141. DOI:10.1061/(ASCE)ST.1943-541X.0001225. 
[15] Zhang, C., Choe, L., Seif, M. and Zhang, Z., Behavior of Axially Loaded Steel Short Columns Subjected to a Localized Fire”, Journal of Constructional Steel Research, 2015 Vol. 111, pp. 103-111.

[16] Li, G.Q. and Zhang, C., "The Chinese Performance-based Code for Fire-resistance of Steel Structures”, International Journal of High-Rise Buildings, 2013, Vol. 2, pp. 123-30.

[17] Li, G.Q. and Zhang, C., "Creep Effect on Buckling of Axially Restrained Steel Columns in Real Fires”, Journal of Constructional Steel Research. 2012, Vol. 71, pp. 182-8.

[18] Welch, S., Miles, S.D., Kumar, S., Lemaire, T. and Chan, A., "Firestruc - Integrating Advanced Three-dimensional Modelling Methodologies for Predicting Thermo-mechanical Behaviour of Steel and Composite Structures Subjected to Natural Fires”, Fire Safety Science, 2008, Vol. 9, pp. 1315-26.

[19] McGrattan, K., Klein B., Hostikka, S., and Floyd J., "Fire Dynamics Simulator (Version 5), User's Guide”, NIST Special Publication 1019-5, National Institute of Standards and Technology, Gaithersburg, MD, USA, 2007.

[20] Li, G.Q. and Zhang, C., “Thermal Response of Steel Columns Exposed to Localized Fires Numerical Simulation and Comparison with Experimental Results”, Journal of Structural Fire Engineering, 2011, Vol. 2, pp. 311-7.

[21] Tondini, N., Vassart, O. and Franssen, J.M., "Development of An Interface between CFD and FE Software”, In Proceedings of the Seventh International Conference on Structures in Fire, pp. 459-68, Zurich, Switzerland, 2012.

[22] Alos-Moya, J., Paya-Zaforteza, I., Garlock, M.E.M., Loma-Ossorio, E., Schiffner, D. and Hospitaler, A., "Analysis of a Bridge Failure due to Fire Using Computational Fluid Dynamics and Finite Element Models”, Engineering Structures, 2014, Vol. 68, pp. 96-110.

[23] Henneton, N., Roosed, M. and Zhao, B., “Application of Structural Fire Safety Engineering to the Canopy of the Forum DES Halles, in Paris", In Proceedings of the 8th International Conference on Structures in Fire, pp. 1047-54, 2014.

[24] Zhang, C., Silva, J.G., Weinschenk, C., Kamikawa, D. and Hasemi, Y., "Simulation Methodology for Coupled Fire-Structure Analysis: Modeling Localized Fire Tests on a Steel Column”, Fire Technology, 2016, Vol.52, pp.239-62.

[25] Hasemi, Y., Yokobayashi, Y., Wakamatsu, T. and Ptchelintsev, A., "Modeling of Heating Mechanism and Thermal Response of Structural Components Exposed to Localized Fires: A New Application of Diffusion Flame Modeling to Fire Safety Engineering”, NIST Internal Report 6030, National Institute of Standards and Technology, Gaithersburg, Maryland, 1997.

[26] Yokubayashi, Y., Hasemi, Y. and Wakamatsu, T., "Experimental Study on the Heating Mechanism and Thermal Response of a Steel Beam under Ceiling Exposed to Localized Fires”, J. Struct. Constr. Eng., AIJ, 1997, Vol. 498, pp. 169-75. (in Japanese).

[27] Wickstrom, U., “The Plate Thermometer - A Simple Instrument for Reaching Harmonized Fire Resistance Tests”, Fire Technology, 1994, Vol. 30, pp. 195-208.

[28] Zhang, C. and Usmani, A., "Heat Transfer Principles in Thermal Calculation of Structures in Fire”, Fire Safety Journal, 2015, Vol. 78, pp. 85-95.

[29] Wickstrom, U., Duthinh, D. and McGrattan, K.B., “Adiabatic Surface Temperature for Calculating Heat Transfer to Fire Exposed Structures”, In Proceedings of the 11 the International Interflam Conference, pp. 943-53, London, England, 2007.

[30] Zhang, C., Li, G.Q. and Wang, R.L., "Using Adiabatic Surface Temperature for Thermal Calculation of Steel Members Exposed to Localized Fires”, International Journal of Steel Structures, 2013, Vol. 13, pp. 547-58.

[31] Wakamatsu, T., Hasemi, Y. and Ptchelintsev, A.V., "Heating Mechanism of Building Components Exposed to a Localizedfire: CFD Prediction of the Heat Flux of a Steel Beam", Fire Science \& Technology. 2000, Vol. 20, pp. 1-12. 